\title{
The Viral Impact of Emotion on Social Transmission Under Control Context
}

\author{
Guiping Zhang ${ }^{1,2 *}$ Xinyue Zhou ${ }^{3 *}$, Jinsong Chen ${ }^{1}$, Yongyuan Gong ${ }^{1}$, Shasha Sun ${ }^{1}$, Xide $\mathbf{Y u}^{1}$ \\ ${ }^{1}$ Department of Psychology, Sun Yat-sen University, Guangzhou, Guangdong, China \\ ${ }^{2}$ Yangcheng Evening News, Guangzhou, China \\ ${ }^{3}$ School of Management, Zhejiang University,HangZhou, China
}

Received: 制: July 23, 2018; Published: 制 August 03, 2018

*Corresponding authors: Guiping Zhang, Department of psychology, Sun Yat- sen university

Xinyue Zhou, School of Management, Zhejiang University, China

\begin{abstract}
This research targeted to investigate the role of emotion in Chinese Social Transmission through an empirical study. Using a unique data set of the Southern Weekly (one of the most famous political media in China) articles published over an 87-days period, we tried to explore the influence of specific emotional attributes on viral forwarding of online content. The results indicate that, although positive emotions generally promote communication, the relationship between emotion and social transmission is more complex than valence alone. Among the 28 emotions common to all Chinese, only 2 emotions (including positive admiration and negative hate/dislike) significantly inhibited transmission. Using special model like the zero-inflated negative binomial (ZINB) regression, the specific emotion (i.e., hate/dislike) can help to distinguish different generating processes for zero-repost articles which are difficult to inform. Taking together, these findings shed light on emotions can predict the virus transmission characteristics of online content under the information control environment.
\end{abstract}

Keywords: Chinese Netizen; Viral Transmission; Online Content; Emotion Attribute; Regime of Information Control

\section{Introduction}

Sharing online content has become an integral part of the lives of Internet users all over the world. The number of Chinese social media users has also grown tremendously in recent years (Weibo 340 million, WeChat 900 million, and QQ 800 million). Social networks in China such as Weibo [1] and WeChat enable the rapid spread of online content among netizens. Affective attributes do affect people's online behaviour [2] and may be influenced by culture. Sharing behavior can lead to emotional infection, and people who are infected are more willing to actively spread [3]. It is well-known that Chinese government publicly restricts information dissemination, and has established its own microcosm of social media trying to closely monitor and control problematic content. Many studies have demonstrated that emotional traits of content will affect whether it is shared [4], then what impact does emotion have on Chinese online communication in China's specific information regulation and cultural background? This article focuses on how emotions affect social transmission in this Chinese context. We analyse a unique data set of 230 Commentary articles in the Southern Weekly, and to examine how content's valence (i.e., whether an article is positive or negative) and the specific emotions it evokes (i.e., admiration, anger/rage, etc., as showed in Table 1 below affect the spontaneously transmission on the social media platform, Weibo. This research makes several important contributions. most of the similar research in the past occurred in
non-Asian regions, and this article focuses on the impact of Chinese general sentiment on online sharing.. By combining a largescale examination of real transmission in the field under tightly controlled context, we shed light on the underlying processes that drive people to share. Second, our findings provide insight into how to design successful viral marketing campaigns and effective communication content under information control environment.

\section{The Current Research}

\section{Data and Analytic Method}

We collected online articles from the Southern Weekly between 2007 and 2011 using a web crawler (during this time period there was relatively less constraint by the government on information dissemination in the Mainland). The retrieval result was a total number of 230 Commentary articles and the number of times they had been reposted on Weibo until 0:00 on December 31, 2014. Rating professionals were employed for the rating-based emotional attributes. As shown in Figure 1, about $40 \%$ of the count data were zeroes. To examine how specific emotions evoked by content drive social transmission, we coded the articles on two dimensions. First, we relied on human coders to classify the extent to which content was exhibited by others, 28 emotional attributes, almost all social emotions most perceived by Chinese. Considering the professional nature of the content [2], we hired twelve media professionals 
instead of students as raters (They included senior reporters, editors, and chairpersons of some newspapers). These raters were all trained and blind to our research hypotheses.

The raters were asked to rate the emotional attributes independently on a binary scale after reading each article, with 1 indicating the activation of the emotional attribute and 0 otherwise. For machine-based emotional indices, the Chinese Linguistic Inquiry and Word Count [9] program was adopted which had been widely used to analyze Chinese text in psychological research [10]. We quantified positivity as the difference between the percentage of positivity and negative words in an article and emotionality as the percentage of both positive and negative words [11]. For machinebased emotional indices based on the CLIWC programme [12], the positivity and emotionality of each article were computed. With count data as the outcome, we employed the negative binomial (NB) regression and the zero-inflated negative binomial (ZINB) regression to analyse the data [13].

The NB distribution is a generalization of the Poisson distribution by allowing over dispersed count data (i.e., different mean and variance). The zero-inflated negative binomial (ZINB) regression to model the probability that some zero-repost articles were different from others in nature. The ZINB regression combines the NB and logistics regression to model count data with excessive zeroes that could be generated by a different process.

Table 1: Descriptive Statistics.

General Predictors

\begin{tabular}{|c|c|}
\hline General Predictors & M \\
\hline Emotionality & 0.02 \\
\hline Positivity & 0.01 \\
\hline Word count/1000 & 1.13 \\
\hline
\end{tabular}

\begin{tabular}{|c|c|}
\hline & \\
\hline & 0.01 \\
0.01 \\
\hline
\end{tabular}

\begin{tabular}{|c|c|c|c|c|c|c|c|}
\hline Positivity & 0.01 & 0.01 & - & hate/dislike & 0.29 & 0.45 & 0.69 \\
\hline Word count/1000 & 1.13 & 0.77 & - & sadness/sorrow & 0.23 & 0.42 & 0.59 \\
\hline \multicolumn{4}{|c|}{ Specific Predictors } & Happiness/joy & 0.08 & 0.27 & 0.53 \\
\hline admiration & 0.4 & 0.49 & 0.66 & disappointment & 0.34 & 0.47 & 0.53 \\
\hline anger/rage & 0.31 & 0.46 & 0.76 & disgust & 0.25 & 0.43 & 0.59 \\
\hline envy & 0.12 & 0.33 & 0.66 & frustration & 0.21 & 0.41 & 0.45 \\
\hline gratitude & 0.18 & 0.42 & 0.4 & fear & 0.14 & 0.39 & 0.58 \\
\hline $\begin{array}{c}\text { gloating/ } \\
\text { schadenfreude }\end{array}$ & 0.04 & 0.21 & 0 & hope & 0.5 & 0.5 & 0.57 \\
\hline jealousy & 0.06 & 0.24 & 0.37 & embarrassment & 0.14 & 0.34 & 0.37 \\
\hline guilt & 0.07 & 0.26 & 0.27 & regret & 0.04 & 0.2 & 0.18 \\
\hline contempt & 0.19 & 0.43 & 0.6 & shyness & 0.06 & 0.32 & 0.01 \\
\hline shame & 0.18 & 0.44 & 0.41 & forgiveness & 0.06 & 0.24 & 0.29 \\
\hline pity/compassion & 0.22 & 0.42 & 0.65 & anxiousness & 0.29 & 0.45 & 0.46 \\
\hline pride & 0.08 & 0.26 & 0.62 & hostility & 0.13 & 0.34 & 0.46 \\
\hline love & 0.27 & 0.44 & 0.63 & self-awareness & 0.42 & 0.56 & 0.21 \\
\hline
\end{tabular}

Table 2: Negative Binomial Regression Models.

\begin{tabular}{|c|c|c|c|c|c|}
\hline & & & Model 1 & Model 2 & Model 3 \\
\hline \multicolumn{6}{|c|}{ General Predictors } \\
\hline Emotionality & $-68.19^{* * *}$ & 14.08 & - & $-36.23^{*}$ & 17.55 \\
\hline Positivity & $144.72^{* * *}$ & 35.93 & - & $146.92^{* *}$ & 33.68 \\
\hline Word count/1000 & 0.12 & 0.31 & - & -0.42 & 0.27 \\
\hline
\end{tabular}

Note: *Significant at $5 \%$ level; ${ }^{* *}$ Significant at $1 \%$ level; ${ }^{* * *}$ Significant at the $.1 \%$ level. 
Table 3: The Results of the ZINB Regressions.

\begin{tabular}{|c|c|c|c|c|c|c|c|c|c|}
\hline & & & Model 2 & & & & & \multirow{2}{*}{\multicolumn{2}{|c|}{$\begin{array}{c}\text { Model } 3 \\
\text { Zero-inflated }\end{array}$}} \\
\hline & \multicolumn{2}{|c|}{ Basic } & & \multicolumn{2}{|c|}{ Zero-inflated } & \multicolumn{2}{|c|}{ Basic } & & \\
\hline General Predictors & & - & & - & & & & & \\
\hline Emotionality & & - & & - & & 0.53 & -24.87 & $54.64 *$ & -26.653 \\
\hline Positivity & & - & & - & & 45.4 & -37.92 & $-99.41^{* *}$ & -35.554 \\
\hline Word count/1000 & & - & & - & & -0.21 & -0.21 & -0.13 & -0.329 \\
\hline Specific Emotions & \multicolumn{2}{|c|}{ Basic } & & \multicolumn{2}{|c|}{ Zero-inflated } & Basic & & \multicolumn{2}{|c|}{ Zero-inflated } \\
\hline admiration & $-1.79 *$ & -0.9 & & 0.442 & -1.29 & $-1.99 *$ & -0.92 & 1.4 & -1.42 \\
\hline Hate/dislike & $-4.28^{* *}$ & -1.61 & & $12.51^{* * *}$ & -2.57 & $-4.20^{* *}$ & -1.6 & $11.75^{* * *}$ & -2.75 \\
\hline$\alpha$ & 1.84 & & & -0.23 & & 1.78 & & & -0.22 \\
\hline Log likelihood & & & -944.8 & & & & & -935.73 & \\
\hline df & & & 28.18 & & & & & 31.23 & \\
\hline
\end{tabular}

Note: only effects significant at $10 \%$ or above level are shown.*Significant at $5 \%$ level; ${ }^{* *}$ Significant at $1 \%$ level; ${ }^{* * *}$ Significant at the .1\% level.

\section{Discussion}

Is positive or negative content more vira under the Chinese information control environment ? the results indicate that the relationship between emotion and social transmission is more complex than valence alone. Online content that evokes positive(admiration) and negative (hate/dislike) emotions may be more suppressed not to be shared by people spontaneously. A negative significant effect in emotionality see Table 2 shows that more affect-laden content, is less likely to be shared. Is it true that up to $40 \% 0$ forwarding means that Chinese really not interested in these articles see Figure 1? Both employing the NB and ZINB regression, and linking psychological and sociological approaches to studying diffusion, when some zero-repost articles were different from others in nature, the findings can help predict the spread of online content in an information control environment. In short, the naturalistic setting allows us to pay attention to the use of emotions and measure the relative importance of content characteristics when we want to increases the likelihood that content will be highly shared in China. Taking together, we examined how the emotionality, valence, and specific emotions evoked by an article can affect its viral transmission and these findings shed light on why people share online content and how to design more effective viral marketing campaigns in China.

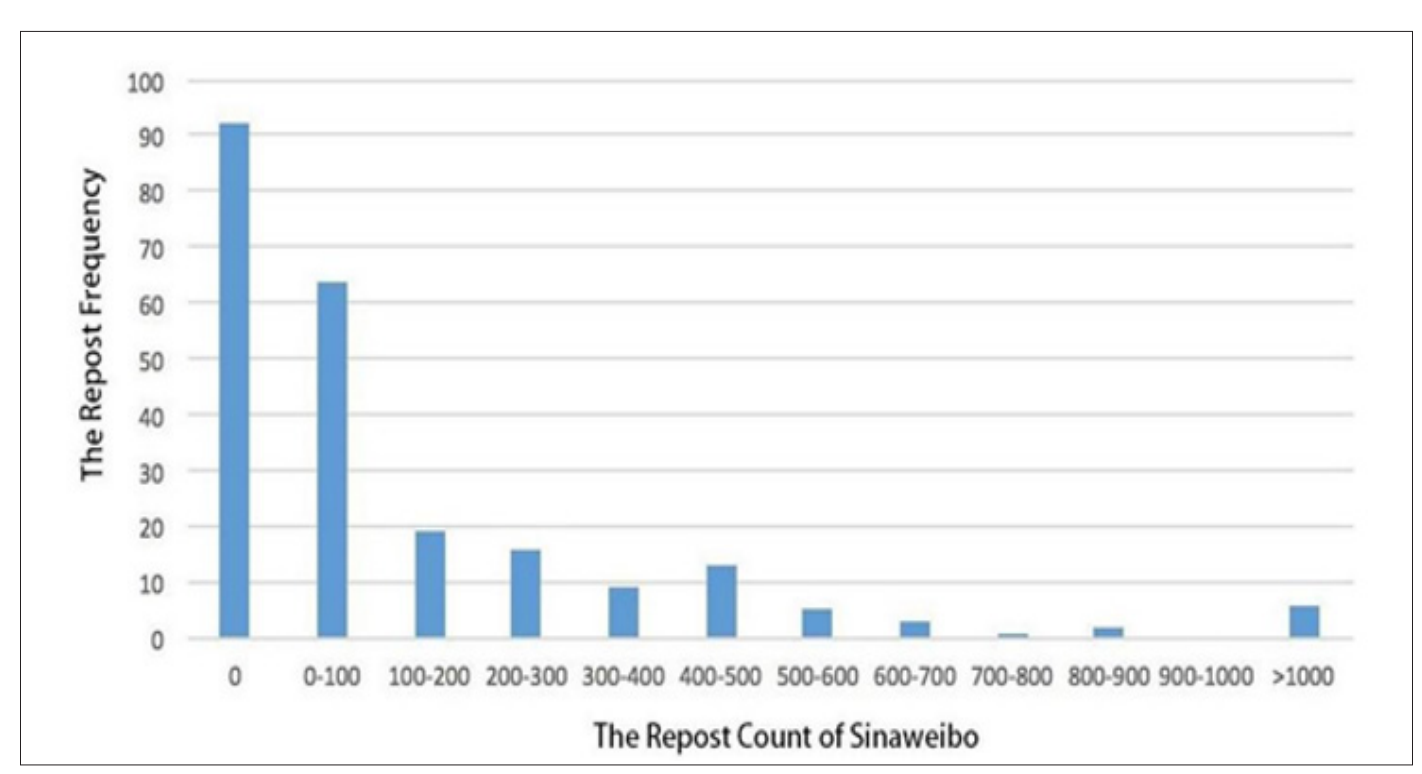

Figure 1: The Distribution of the Data against the Reposts.

\section{Acknowledgements}

This research was supported by National Natural Science Foundation of China[31771239] and also by Guangdong Province philosophy and social science planning project. Grant No.: GD17HJY01.We greatly appreciate Zijun Ke, Xiling Xiong, and Siyuan Guo for their invaluable research assistance. 


\section{References}

1. Sullivan J (2014) China's Weibo: Is faster different? New Media \& Society 16(1): 24-37.

2. Hareli S, Parkinson B (2008) What's social about social emotions? Journal for the Theory of Social Behavior, 38(2): 131-156.

3. Allsop, Dee T, Bryce R, Bassett, James A, et al. (2007) "Word-of-Mouth Research: Principles and Applications" .Journal of Advertising Research 47(4): 388-411.

4. Heath C, Bell C, Sternberg E (2001) Emotional selection in memes: the case of urban legends. Journal of personality and social psychology 81(6): 1028-1041.

5. Kim S, Bak J, Oh AH (2012) Do you feel what I feel? Social aspects of emotions in Twitter conversations. In ICWSM.

6. Pennebaker JW, Zech E, Rimé B (2001) Disclosing and sharing emotion: Psychological, social, and health consequences. Handbook of bereavement research: Consequences, coping, and care pp. 517-543.

7. Smith CA, Ellsworth PC (1985) Patterns of cognitive appraisal in emotion. Journal of personality and social psychology 48(4): 813-838.

ISSN: 2574-1241

DOI: 10.26717/BJSTR.2018.07.001499

Guiping Zhang, Xinyue Zhou. Biomed J Sci \& Tech Res

(C) $(1)$ This work is licensed under Creative

Submission Link: https://biomedres.us/submit-manuscript.php
8. Huang CL, Chung CK, Hui N, Lin YC, Seih YT, et al. (2012) The development of the Chinese linguistic inquiry and word count dictionary. Chinese Journal of Psychology 54(2): 185-201.

9. Gao R, Hao B, Li H, Gao Y, Zhu T, et al. (2013) Developing simplified Chinese psychological linguistic analysis dictionary for microblog. Lecture Notes in Computer Science p. 359-368.

10. Pennebaker JW, Booth RJ, Francis ME (2007) Linguistic inquiry and word count: LIWC [Computer software]. Austin.

11. Lawrence R, Melville P, Perlich C, Sindhwani V, Meliksetian S, Pei-Yun $\mathrm{H}$, et al. (2017) Social media analytics. Business \& Information Systems Engineering, 6(2): 89-96.

12. Scott Long J (1997) Regression models for categorical and limited dependent variables. Advanced quantitative techniques in the social sciences p. 7.

13. Stroebe, H Schut (Eds.) Handbook of bereavement research: Consequences, coping, and care. pp. 517-543.

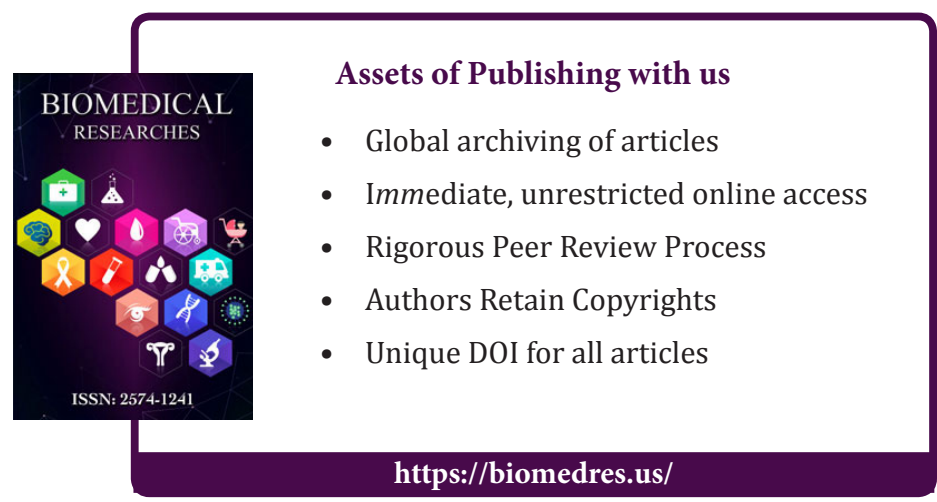

